
\title{
25 Research Square \\ The Role of MicroRNA-155 in Glomerular Endothelial Cell Injury of Diabetic Nephropathy
}

\section{Kaiying He ( $\nabla 1694851684 @ q q . c o m)$}

Lanzhou University https://orcid.org/0000-0002-9389-8387

\section{Zhan Chen}

Zhengzhou University

\section{Jing Zhao}

Lanzhou University

\section{Yang He}

Lanzhou University

\section{Rongrong Deng}

Lanzhou University Second Hospital

\section{Xin Fan}

Lanzhou University

\section{Xiaochun Zhou}

Lanzhou University Second Hospital

Jianqin Wang

Lanzhou second hospital

\section{Research Article}

Keywords: Diabetic Nephropathy, Human Glomerular Endothelial Cells, MiR-155, ETS-1.

Posted Date: November 3rd, 2021

DOI: https://doi.org/10.21203/rs.3.rs-981690/v1

License: (c) (1) This work is licensed under a Creative Commons Attribution 4.0 International License.

Read Full License 


\section{Abstract}

Objective: To investigate the role of microRNA-155-5p (miR-155-5p) on apoptosis and inflammatory response in human glomerular endothelial cells (HRGEC) cultured with high glucose.

Methods: The primary human glomerular endothelial cells (HRGEC) were studied, QPCR, WB , IF were used to detect cell morphology, target gene ETS-1 (ETS-1), downstream factors VCAM-1 and MCP-1, and apoptosis of cells in each group after high glucose stimulation and transfection with miR-155 overexpression or inhibitor.

Results:

1.The expression of inflammatory factors and apoptosis of HRGEC cells increased under high glucose stimulation.

2.The overexpression of miR-155 in HRGEC cells under high glucose stimulation decreased the expression of ETS-1, while the expression of ETS-1 increased when miR-155 was inhibited. These results suggest that miR-155 may be involved in endothelial cell injury by negatively regulating the expression of ETS-1.

3.HRGEC cells were transfected with miR-155 mimic and ETS-1 siRNA with high glucose stimulation. The expression of ETS-1 was positively correlated with the expression of downstream factors VCAM-1 and MCP-1. These results suggest that ETS-1 can mediate endothelial cell inflammation by regulating VCAM1 and MCP-1.

\section{Introduction}

Diabetic nephropathy (DN) is a specific complication of long-term poor blood glucose control, which may lead to progressive renal function damage and cardiovascular risk [1-2]. Nowadays, DN is the main cause of adult ESRD, which brings heavy burden to our country and society. Current studies indicate that the DN is caused by a combination of multiple factors, such as elevated blood glucose, changes in renal hemodynamics caused by hypertension, ethnic risk, genetic and metabolic interactions, etc [3]. In recent years, the molecular level of DNA methylation, chromatin histone modification, new transcripts and functional non-coding RNAs, for example, microRNA and long non-coding RNA have been rapidly studied in the fields of glomerular immune inflammatory response, epithelial mesenchymal transformation, cell apoptosis, mitochondrial damage, podocyte endothelial cell interaction, etc[4-7]. However, there is still no conclusion on the occurrence and progress of DN. Therefore, it is urgent to further study the pathogenesis of DN and find more specific biomarkers and targets to assist in the early diagnosis and treatment of DN at the gene level [8-9]. This study selected the primary human glomerular endothelial cells as the research object, because it is located in the glomerular capillary the innermost, and it is vulnerable to the blood sugar, blood lipids, the stimulation of inflammation factors such as damage [10], Injury of endothelial cells lead to abnormal secretion of related cytokines acting on adjacent potocytes and 
mesangial cells, leading to a vicious cycle, which result in increased production of extracellular matrix, thickening of basement membrane, and interstitial fibrosis aggravating glomerulosclerosis [11-13]. Therefore, the in-depth study on the injury mechanism of glomerular endothelial cells in DN is of great significance for finding new targets.

MicroRNAs are small endogenous non-coding RNA with a length of about 20bp, which bind to the 3 'untranslated region of mRNA of target genes through base complementary pairing, thereby degrading mRNA or inhibiting its translation and regulating downstream protein expression. Multiple studies have shown that microRNA plays an important role in cell proliferation, apoptosis, inflammation, accumulation of extracellular matrix, glomerular fibrosis and the occurrence and development of diabetes [14-20]. MicroRNA, as a new biomarker, has been widely studied and plays an important role in inducing injury of endothelial cells and podocyte as well as the occurrence and development of diabetic nephropathy. It has high potential application value in the early diagnosis and treatment of DN. Previous studies have shown that miR-155 as a multifunctional miRNA, plays an important role in cell differentiation and proliferation, inflammation, apoptosis and autophagy [21-25]. Huang et al. [26] found that miR-155 expression was increased in renal tissues of DN patients, and mainly expressed in glomerular vascular endothelial cells, mesangial cells and renal tubule interstitium. The results of luciferase reporter gene showed that ETS1(E26 transformation-specific Sequence 1) may be a potential target gene of miR-155. Further detection of serum miRNAs in diabetic patients showed abnormal expression of miR-155 in diabetic patients compared with healthy controls, and the expression of miR-155 was significantly different in microproteinuria and macroproteinuria groups, and was positively correlated with eGFR in DN patients and negatively correlated with urinary protein excretion rate.

Based on the current theoretical understanding and previous research of our group, we speculated that circulating miR-155 may be involved in the occurrence of DN by regulating ETS- 1 and is related to the injury of glomerular endothelial cells in diabetic nephropathy. As the mechanism of miR-155 in glomerular endothelial cell injury of diabetic nephropathy is poorly understood, our study intends to construct a transfection model of human glomerular endothelial cells with miR-155 mimic/inhibitor under high glucose. In order to further understand the role of miR-155 in diabetic glomerular vascular endothelial injury, and initially clarify its mechanism. It provides experimental basis for clinical early warning and early diagnosis of diabetic nephropathy, as well as finding new targets for intervention, and it has important scientific value and clinical significance for the prevention and treatment of diabetic nephropathy.

\section{Materials And Methods}

1.Cells: The primary human glomerular endothelial cells (HRGEC) used in this study were all purchased from ScienCell Research Laboratory (ART. 4000, Lot. 20522), which can provide the primary cell identification report. HRGEC was cultured in precoated flask with fibrin coating solution and ECM medium containing $5 \%$ serum, $1 \%$ growth factor, $1 \%$ Penicillin-Streptomycin solution, and placed in an incubator with $5 \% \mathrm{CO} 2$ at $37^{\circ} \mathrm{C}$. When the cell culture reached about $90 \%$ fusion, the passage was carried out. 
2.miRNA transfection: In 25T flask, according to the instructions of riboFECTTMCP transfection reagent, 50nM miRNA-155 mimics and mimic negative control, 100nM inhibitor and inhibitor negative control were transfected into HRGEC cells respectively, and the transfected cells were obtained at specified time to detect cell apoptosis, expression of inflammatory factors and miR-155 levels.

3.QRT-PCR: Total RNA was extracted by Trizol, after RNA concentration was measured, cDNA synthesis was performed using reverse transcription kit (TakaRa). QPCR was performed to detect miR-155 levels and mRNA levels of related factors.

4. Western Blot: The cells or tissues were lysed with protein lysis buffer, and the loading buffer was added and heated for denaturation. The protein samples were subjected to electrophoresis, electrortansfer, sealing, and incubation with primary and secondary antibodies. The absorbance of the protein bands was scanned and analyzed in a gel image analysis system using enhanced chemiluminescence (ECL, Millipore) system.

5.Cell immunofluorescence: Cell slipper in 24 -well plate was cultured in $37^{\circ} \mathrm{C}$ sterile $\mathrm{CO} 2$ incubator until $80 \%$ cells were fused, and different treatments were carried out for each experimental group according to the experimental scheme. After 48-72h induction, the cells were fixed with 4\% PFA for 40min, then washed with DPBS, $0.3 \%$ TritonX-100 permeable cells for 30min, and 3\% BSA blocked for 20min. Fluorescent primary antibody was incubated at $4{ }^{\circ} \mathrm{C}$ for $12 \mathrm{~h}$, and fluorescent secondary antibody was incubated at room temperature for $2 \mathrm{~h}$, then washed with DPBS. The images were taken under confocal laser microscope after dye nuclear with DAPI and sealing.

6.Statistical analysis: SPSS (Statistical Program for Social Sciences) 20.0 software was used for Statistical analysis of the data in this paper. The measurement data were expressed as mean \pm standard deviation $(X \pm S)$. Two independent sample $T$ tests were used to compare the two groups. Univariate anOVA was used to compare the groups. The Least Significant Difference (LSD-T) test was used for pairwise comparison between multiple groups. $\mathrm{P} \leq 0.05$ was considered as significant and statistically significant.

\section{Results}

1.Light microscope results of cell growth condition after hyperosmolar, high glucose and transfection with miR-155

In this study, endothelial cell damage in diabetic nephropathy was investigated. In order to simulate the high glucose and high osmotic environment, the concentration of D-glucose or mannitol was added to ECM medium to reach $30 \mathrm{mmol} / \mathrm{L}$. miR-155 was transfected after high-glucose stimulation. After 48h of stimulation, cells in each group were changed with fresh culture medium to observe and photograph under light microscope. It was found that cells in the normal glucose (NG), high mannitol (HM) and high glucose $(\mathrm{HG})$ groups had good growth state, full morphology and tight intercellular connections. The cell density could reach $100 \%$ after 3 days of subculture. Compared with NG, HM and HG groups, cell density 
in the transfection group was reduced, cell membranes were folded, granular substances appeared in cytoplasm and nucleus, and cell morphology was changed, (shown in Fig. 1). In addition, compared with $\mathrm{HM}, \mathrm{HG}$ and transfection control group, a large number of intact and adherent round bubble cells were found in miR-155 inhibitor group, but no such cells were found in HM and HG group, and few cells in miR155 mimic group. It is speculated that these bubble cells may be vacuolated changes of cells in the early stage of apoptosis (shown in Fig. 2).

2.The expression level of miRNA-155 in endothelial cells stimulated by high glucose

After high glucose, high osmotic and normal glucose stimulation for $24 \mathrm{~h}$, the total RNA was extracted. QPCR was used to verify the expression of miRNA-155 under different stimulation. The expression of miRNA-155 in HG group is significantly higher than NG group and $H M$ group $(P<0.05$, shown in Fig. 3$)$.

3.The expression level of miRNA-155 in HRGEC cells after transfection

HRGEC cells were transfected with miR-155 mimic control, miR-155 mimic, miR-155 inhibitor control and miR-155 inhibitor respectively (The sequence is shown in Table 1). QPCR was used to verify the transfection efficiency. The results of QPCR showed that the expression of miR-155 in miR-155 mimic group was significantly higher than that in the control group $(P<0.05)$, in addition, the expression of miR155 in miR-155 inhibitor group is significantly lower than that in the control group $(P<0.05$, shown in Fig. 4).

4.Effects of high glucose stimulation on expression levels of inflammation and apoptosis-related proteins in endothelial cells

The HRGEC cells were cultured with high glucose, high osmotic or normal glucose, meanwhile the RNA and the protein were extracted after $24 \mathrm{~h}, 48 \mathrm{~h}$ respectively. QPCR results showed that compared with NG and HM groups, the mRNA levels of ETS-1, Vascular Cell Adhesion Molecule 1(VCAM-1), Monocyte Chemotactic Protein 1 (MCP-1) and apoptosis related Protein, such as Cleaved caspase-3 were greatly increased, which was statistically significant $(P<0.05$, shown in Fig. 5 The primer sequence is shown in Table 2).Western blotting and quantitative analysis showed that ETS-1, VCAM-1, MCP-1 and Cleaved caspase-3 were significantly different in the HG group compared with NG and HM groups, with statistical significance $(P<0.05)$, while there was no significant difference between $N G$ and $H M$ groups (shown in Fig. 6). The results of immunofluorescence showed that ETS-1 was expressed in the nucleus, VCAM-1 and MCP-1 in the cytoplasm. After HGERC cells were stimulated by high glucose, the fluorescence of ETS1, VCAM-1 and MCP-1 was enhanced, and the results were consistent with western-blot results (shown in Fig. 7).

5.Effects of miR-155 transfection under high glucose stimulation on ETS-1, endothelial cell inflammation and apoptosis

In order to determine the effects of miR-155 on ETS-1, endothelial cell inflammation and apoptosis, glomerular endothelial cells were transfected with miR-155 mimic, miR-155 inhibitor, mimic control and 
inhibitor control with high glucose stimulation. The corresponding RNA and protein were extracted $24 \mathrm{~h}$ and $48 \mathrm{~h}$ after transfection. QPCR results showed that the mRNA levels of ETS-1, VCAM-1, MCP-1 and Cleaved caspase-3 mRNA in miR-155 mimic group were decreased compared with the control group; meanwhile, the mRNA levels of those mRNA increased in miR-155 inhibitor group, which was statistically significant $(P<0.05$, shown in Fig. 8). Western-blot and quantitative analysis showed that the protein expression levels of ETS-1, VCAM-1, MCP-1 and Cleaved caspase-3 in miR-155 mimic and miR-155 inhibitor group were significantly different compared with the control group $(P<0.05)$. There was no significant difference between mimic control and inhibitor control group and high glucose control group (shown in Fig. 9). The results of cell immunofluorescence and quantitative analysis were consistent with those of Western-blot (shown in Fig. 7).

\section{Regulation of downstream effector factors by inhibition of ETS-1 in high glucose stimulation}

In order to further clarify the regulation of ETS-1 on downstream effector factors VCAM-1 and MCP-1, ETS-1 siRNA and scramble RNA were transfected into glomerular endothelial cells with high-glucose. QPCR results showed that the mRNA levels of ETS-1, VCAM-1 and MCP-1 in the ETS-1 siRNA group were significantly decreased compared with the control group, with statistical significance $(P \leq 0.05)$, and there was no significant difference between the scramble RNA group and the high-glucose control group (shown in Fig. 10). Western-blot and quantitative analysis showed that the protein expressions of ETS-1, VCAM-1 and MCP-1 in the ETS-1 siRNA group were significantly decreased compared with the control group, with statistically significant differences $(P \leq 0.05)$, while there was no significant difference between the scramble RNA group and the high-glucose control group (shown in Fig. 11). The results of cell immunofluorescence and quantitative analysis were consistent with those of Western-blot (shown in Fig. 11).

\section{Discussion}

Mir-155 is a typical multifunctional miRNA, which plays a crucial role in the regulation of numerous cells and blood vessels. However, its mechanism on endothelial cell dysfunction has not been fully clarified. Existing studies have shown that miR-155 is involved in cell differentiation, proliferation, inflammation, immunity, tumorigenesis, autophagy, apoptosis, and the development regulation of a variety of biological tissues [21-25].In this study, primary human glomerular endothelial cells stimulated by high glucose were selected to simulate the internal environment during the occurrence of diabetes mellitus, and the regulation of miR-155 on ET-1 and downstream factors was studied by transfected endothelial cells with miR-155 mimics or inhibitor.

At present, the specific target gene of miR-155 is not clear. The results of online gene prediction software TargetScan and double luciferase reporter gene in the early stage of our research group indicate that ETS1 may be the target gene related to miR-155 in DN. ETS-1 (E26 transformation-specific Sequence 1) belongs to the E26 transformation-specific transcription factor superfamily. As a proto-oncogene, it can be upregulated by angiotensin II (Ang II) in the vascular system and glomerulus to promote inflammatory 
response [27-28]. In addition, it plays an important role in regulating energy metabolism, vascular development and generation, vascular inflammation and remodeling of cancer cells [29-30]. Its target genes include receptor tyrosine kinases, MMPs and intercellular adhesion molecules. As an endothelial adhesion receptor, Vascular cell adhesion molecule 1 (VCAM-1) plays an important role in leukocyte recruitment in cellular immune response, at the same time, it can promote the adhesion of leukocytes to vascular wall and induce inflammation. It is also associated with tumor growth, metastasis and angiogenesis [31]. Monocyte chemotactic protein 1 (MCP-1) is a member of the CC subfamily of chemokines, which can chemotactic monocytes, $T$ lymphocytes, macrophages, and affect their phagocytosis as well as antibody production [32].IL-1 induces MCP-1 production in glomerular cells during renal inflammation. In hyperlipidemia, LDL binds to glomerular cells to stimulate their production of MCP-1 and chemotactic monocytes. Zhu et al. [33] showed that ETS-1 and its downstream factors FLT1, MCP-1 and VCAM-1 were up-regulated after Ang II stimulated umbilical vein endothelial cells, while overexpression of miR-155 and miR-221 partially reversed this effect. Therefore, we believe that ETS-1, VCAM-1, MCP-1 may play an important role in inflammatory response, angiogenesis and extracellular matrix deposition during the development of DN.

Therefore, different methods were adopted in this study to verify the regulation of miR-155 on ETS-1 and downstream factors VCAM-1, MCP-1 by overexpression or inhibition of Mir-155 on human glomerular endothelial cells cultured with high glucose. It was found that after high glucose stimulated endothelial cells, QPCR, Western blotting, and immunofluorescence results showed that the expressions of ETS-1, VCAM-1, McP-1, and cleaved caspase-3 were increased, further indicating that high glucose can induce endothelial cell inflammation and apoptosis. After transfection with Mir-155 mimics or inhibitor, Western blotting and immunofluorescence showed that the expression of ETS-1 decreased when miR-155 was overexpressed, and increased when miR-155 was inhibited. The targeted regulation of miR-155 on ETS- 1 was preliminatively verified. Meanwhile, VCAM-1, MCP-1, Cleaved caspase-3 protein expression showed the same trend as ETS-1. To further verify the regulation of ETS-1 on downstream factors VCAM-1 and MCP-1, ETS-1 siRNA was transfected into endothelial cells. The results showed that the expression of ETS-1 and its downstream factors (VCAM-1, MCP-1) were down-regulated in the ETS-1 siRNA group and miR-155 mimic group. Therefore, miR-155 can negatively regulate the expression of ETS-1 and then act on MCP-1, VCAM-1 to participate in the inflammatory response of DN. In terms of cell apoptosis, Liao et al. [34] reported that miR-155 is up-regulated in hepatocellular carcinoma, and the up-regulated miR-155 can target FoxO3a expression and then inhibit bcl-2, caspase- 3 and caspase- 9 activities, thus inhibiting cell apoptosis and promoting cell proliferation in patients with hepatocellular carcinoma. Xu et al. [35] found that down-regulation of miR-155 can significantly inhibit proliferation, migration, invasion and promote apoptosis of psoriatic cells through the PTEN signaling pathway. In this study, mir-155 overexpression in endothelial cells could inhibit cleaved caspase 3 expression and thus inhibit apoptosis of endothelial cells.

In addition, there are still some limitations and deficiencies in this study. Firstly, only one target gene of miR-155 was involved in this study, while miRNAs simultaneously regulate multiple target genes in vivo, and there is a lack of miR-155 overexpression or knockout mouse model to clarify the regulatory effect of 
miR-155 in animals. Secondly, classical flow cytometry and TUNEL analysis were not used to explain the regulatory effect of miR-155 on endothelial cell apoptosis. Therefore, it is still necessary to further study the relationship between miR-155 and the development of DN, so as to provide new ideas for basic and clinical research about DN.

Combined with relevant reports, this study initially concluded that miR-155 in diabetic glomerular endothelial cells may mediate endothelial cell damage through negative regulation of target gene ETS-1 and downstream factors VCAM- 1 and MCP-1. Meanwhile, miR-155 can negatively regulate the expression of apoptosis-related protein Cleaved caspase-3 and participate in endothelial cell apoptosis, so miR-155 is expected to serve as a marker of endothelial cell injury in diabetic nephropathy. At present, this study is relatively limited, and animal experiments and large-sample clinical studies are still needed as support to further reveal the role of miR-155 in the development of DN and provide a new path for the early diagnosis and treatment of DN.

\section{Conclusion}

MiR-155 can negatively regulate the expression of target gene ETS- 1 and its downstream factors VCAM-1 and MCP-1, thus mediating the inflammatory response and apoptosis of HRGEC.

\section{Declarations}

\section{Statement of Ethics}

This study passed the review of Ethics Committee of the Second Hospital of Lanzhou University. The study approval reference numberख2015B-002.

\section{Conflict of Interest Statement}

The authors declare that they have no competing interests.

\section{Acknowledgments}

We thank Dr. jianqin Wang for his helpful suggestions regarding the experiments and his excellent technical assistance.

\section{Funding Sources}

This work was supported in part by the Special Fund for Basic Research on Scientific Instruments of the National Natural Science Fundation of China (No.81960142), and from Youth Science and Technology Fund program of Gansu Province (No.438002465 21JR1RA157/85).

\section{Authors Contributions}

Author contributions: 
Xiaochun Zhou, Jianqin Wang contributed to the conception of the study;

Kaiying He, Zhan Chen performed the experiment;

Jing Zhao contributed significantly to analysis and manuscript preparation;

Yang He performed the data analyses and wrote the manuscript;

Rongrong Deng, Xin Fan helped perform the analysis with constructive discussions.

\section{Data Availability Statement}

All data generated or analysed during this study are included in this article. Further enquiries can be directed to the corresponding author.

\section{References}

[1] Shaw J E, Sicree R A, Zimmet P Z. Global estimates of the prevalence of diabetes for 2010 and 2030[J]. Diabetes Research \& Clinical Practice, 2010, 87(1):4-14.

[2] Xu Y1, Wang L, He J,Bi Y, Li M, Wang T, Wang L, Jiang Y, Dai M, Lu J, Xu M, Li Y, Hu N, Li J, Mi S, Chen CS, Li G, Mu Y, Zhao J, Kong L, Chen J, Lai S, Wang W, Zhao W, Ning G. Prevalence and control of diabetes in Chinese adults. JAMA, 2013,310(9):948-959.

[3] Wang T, Xu Y, Xu M, et al. Awareness, treatment and control of cardiometabolic disorders in Chinese adults with diabetes: a national representative population study[J]. Cardiovascular Diabetology, 2015, 14(1):28.

[4] Satchell S C, Braet F. Glomerular endothelial cell fenestrations: an integral component of the glomerular filtration barrier[J]. American Journal of Physiology - Renal Physiology, 2009, 296(5):F947F956.

[5] Salmon A H, Ferguson J K, Burford J L, et al. Loss of the endothelial glycocalyx links albuminuria and vascular dysfunction[J]. Journal of the American Society of Nephrology Jasn, 2012, 23(8):1339.

[6] Richard A. Lafayette, Maurice Druzin, Richard Sibley, et al. Nature of glomerular dysfunction in preeclampsia 1[J]. Kidney International, 1998, 54(4):1240-1249.

[7] Fridén V, Oveland E, Tenstad O, et al. The glomerular endothelial cell coat is essential for glomerular filtration[J]. Kidney International, 2011, 79(12):1322-30.

[8] Sung S H, Ziyadeh F N, Wang A, et al. Blockade of vascular endothelial growth factor signaling ameliorates diabetic albuminuria in mice[J]. Journal of the American Society of Nephrology, 2006, 17(11):3093-3104.

[9] A. Kuwabara, M. Satoh, N. Tomita, et al. Deterioration of glomerular endothelial surface layer induced by oxidative stress is implicated in altered permeability of macromolecules in Zucker fatty rats[J]. 
Diabetologia, 2010, 53(9):2056-2065.

[10] HansPeter Hammes, Yuxi Feng, Frederick Pfister, et al. Diabetic Retinopathy: Targeting Vasoregression[J]. Diabetes, 2011, 60(1):9-16.

[11] M Mizutani, T S Kern, M Lorenzi. Accelerated death of retinal microvascular cells in human and experimental diabetic retinopathy.[J]. Journal of Clinical Investigation, 1996, 97(12):2883-90.

[12] Park D Y, Lee J, Kim J, et al. Plastic roles of pericytes in the blood-retinal barrier[J]. Nature Communications, 2017, 8:15296.

[13] la V D O, Raterman H G, Nurmohamed M T, et al. Endothelial dysfunction, inflammation, and apoptosis in diabetes mellitus.[J]. Mediators of Inflammation,2010,(2010-05-03), 2010, 2010(1):792393.

[14] Maric-Bilkan C, Flynn E R, Chade A R. Microvascular disease precedes the decline in renal function in the streptozotocin-induced diabetic rat[J]. American Journal of Physiology Renal Physiology, 2012, 302(3):F308.

[15] Lindenmeyer M T, Kretzler M, Boucherot A, et al. Interstitial vascular rarefaction and reduced VEGF-A expression in human diabetic nephropathy[J]. Journal of the American Society of Nephrology Jasn, 2007, 18(6):1765.

[16] Sivaskandarajah G A, Jeansson M, Maezawa Y, et al. Vegfa Protects the Glomerular Microvasculature in Diabetes[J]. Diabetes, 2012, 61(11):2958-2966.

[17] Isermann B, Vinnikov IA, Madhusudhan T, et al. Activated protein C protects against diabetic nephropathy by inhibiting endothelial and podocyte apoptosis. [J]. Nature Medicine, 2007, 13(11):13491358.

[18] Weil EJ, Lemley KV, Mason CC, Yee B, Jones LI, Blouch K, LovatoT, Richardson M, Myers BD, Nelson RG. Podocyte detachment and reduced glomerular capillary endothelial fenestration promote kidney disease in type 2 diabetic nephropathy. Kidney Int 82: 1010-1017, 2012.

[19] Kameda $Y$, Babazono T, Uchigata $Y$, et al. Renal function after intravitreal administration of vascular endothelial growth factor inhibitors in patients with diabetes and chronic kidney disease:[J]. Journal of Diabetes Investigation, 2018, 9(4):937-939.

[20] Erturk I, Yesildal F, Acar R, et al. Vascular endothelial growth factor and soluble vascular endothelial growth factor receptor-1 in patients with end-stage renal disease:Associations with laboratory findings, comorbidities, and medications[J]. Saudi Medical Journal, 2018, 39(6):586-591.

[21] Suzuki Y, Montagne K, Nishihara A, et al. BMPs Promote Proliferation and Migration of Endothelial Cells via Stimulation of VEGF-A/VEGFR2 and Angiopoietin-1/Tie2 Signalling[J]. Journal of Biochemistry, 2008, 143(2):199-206. 
[22] Gnudi L. Angiopoietins and diabetic nephropathy[J]. Diabetologia, 2016, 59(8):1616-1620.

[23] Dessaptbaradez C, Woolf A S, White K E, et al. Targeted glomerular angiopoietin-1 therapy for early diabetic kidney disease.[J]. Journal of the American Society of Nephrology Jasn, 2014, 25(1):33.

[24] Rizkalla B, Forbes J M, Cao Z, et al. Temporal renal expression of angiogenic growth factors and their receptors in experimental diabetes: role of the renin-angiotensin system.[J]. Journal of Hypertension, 2005, 23(1):153-64.

[25] Marie Jeansson, Alexander Gawlik, Gregory Anderson, et al. Angiopoietin-1 is essential in mouse vasculature during development and in response to injury. $\mathrm{J}$ Clin Invest[J]. Journal of Clinical Investigation, 2011, 121(6):2278-2289.

[26] Mikhail M, Vachon PH, D'OrleansJuste P, et al. ROLE OF ENDOTHELIN-1 AND ITS RECEPTORS ETA AND ETB IN THE SURVIVAL OF HUMAN VASCULAR ENDOTHELIAL CELLS.[J]. Canadian Journal of Physiology and Pharmacology, 2017, 95(10).

[27] Zhong F, Chen $\mathrm{H}$, Wei C, et al. Reduced Kruppel-like factor 2 expression may aggravate the endothelial injury of diabetic nephropathy[J]. Kidney International, 2015, 87(2):382-395.

[28] Zhang X, Sun D, Song J W, et al. Endothelial cell dysfunction and glycocalyx - A vicious circle[J]. Matrix Biology, 2018.

[29] Sieve I, Munster-Kuhnel A, Hilfiker-Kleiner D. Regulation and function of endothelial glycocalyx layer in vascular diseases[J]. Vascular Pharmacology, 2017, 100.

[30] Salmon A H, Satchell S C. Endothelial glycocalyx dysfunction in disease: albuminuria and increased microvascular permeability[J]. Journal of Pathology, 2012, 226(4):562-574.

[31] Floege J, Eitner F, Alpers C E. A New Look at Platelet-Derived Growth Factor in Renal Disease[J]. Journal of the American Society of Nephrology, 2008, 19(1):12-23.

[32] LindahI P, Hellström M, Kalén M, et al. Paracrine PDGF-B/PDGF-Rbeta signaling controls mesangial cell development in kidney glomeruli.[J]. Development, 1998, 125(17):3313.

[33] Bjarnegård $M$, Enge $M$, Norlin J, et al.Endothelium-specific ablation of PDGFB leads to pericyte loss and glomerular, cardiac and placental abnormalities.[J]. Development, 2004, 131(8):1847-1857.

[34] Figueira M F, Monnerat-Cahli G, Medei E, et al. MicroRNAs: potential therapeutic targets in diabetic complications of the cardiovascular and renal systems[J]. Acta Physiologica, 2014, 211(3):491-500.

[35] Mu J, Pang Q, Guo Y H, et al. Functional implications of microRNA-215 in TGF- $\beta 1$-induced phenotypic transition of mesangial cells by targeting CTNNBIP1.[J]. Plos One, 2013, 8(3):e58622.[58] 


\section{Tables}

Table 1 Sequences of miR-155 mimic/inhibitor/mimic NC/inhibitor NC for transfection in this study

\begin{tabular}{|lll|}
\hline & sense & antisense \\
\hline $\begin{array}{l}\text { hsa-miR-155-5p } \\
\text { mimic }\end{array}$ & $5^{\prime}$-UUAAUGCUAAUCGUGAUAGGGGUU- & $\begin{array}{l}5^{\prime} \text { - } \\
\text { AACCCCUAUCACGAUUAGCAUUAA- } \\
3^{\prime}\end{array}$ \\
$\begin{array}{l}\text { hsa-miR-155-5p } \\
\text { inhibitor }\end{array}$ & $5^{\prime}$-AACCCCUAUCACGAUUAGCAUUAA-3' & \\
\hline mimic NC & $5^{\prime}$-UUUGUACUACACAAAAGUACUG-3' & $\begin{array}{l}5^{\prime}-\text {-CAGUACUUUUGUGUAGUACAAA- } \\
3^{\prime}\end{array}$ \\
\hline inhibitor NC & 5'-CAGUACUUUUGUGUAGUACAAA-3' & \\
\hline
\end{tabular}

Table2 Sequences of primers for qRT-PCR in this study 


\begin{tabular}{|c|c|c|}
\hline Gene & Sequences & \\
\hline \multirow[t]{2}{*}{ ETS-1 } & Sense & 5'-GAAGGATGGGCAAATCTGGTC-3' \\
\hline & Antisense & 5'-GAATGGAGAAGGGAACAAAAGTGA-3' \\
\hline \multirow[t]{3}{*}{ VCAM-1 } & Sense & 5'-TCGTGAAACATCTCCGTACCA \\
\hline & & $-3^{\prime}$ \\
\hline & Antisense & 5'-TAATAAGCAAAGGGAGCACTGG-3' \\
\hline \multirow[t]{4}{*}{ MCP-1 } & Sense & 5'-GCAATCAATGCCCCAGTCA \\
\hline & & $-3^{\prime}$ \\
\hline & Antisense & 5'-ACACTTGCTGCTGGTGATTCTT \\
\hline & & $-3^{\prime}$ \\
\hline \multirow[t]{4}{*}{ Cleaved caspase-3 } & Sense & 5'-TACTССTTCCATCAAATAGAACCAC \\
\hline & & $-3^{\prime}$ \\
\hline & Antisense & 5'-TCATAATGACTGCACCAGTATCCA \\
\hline & & $-3^{\prime}$ \\
\hline \multirow[t]{4}{*}{ GAPDH } & Sense & 5'-CCAGCAAGAGCACAAGAGGA \\
\hline & & $-3^{\prime}$ \\
\hline & Antisense & 5'-GTCTACATGGCAACTGTGAGGAG \\
\hline & & $-3^{\prime}$ \\
\hline
\end{tabular}

\section{Figures}



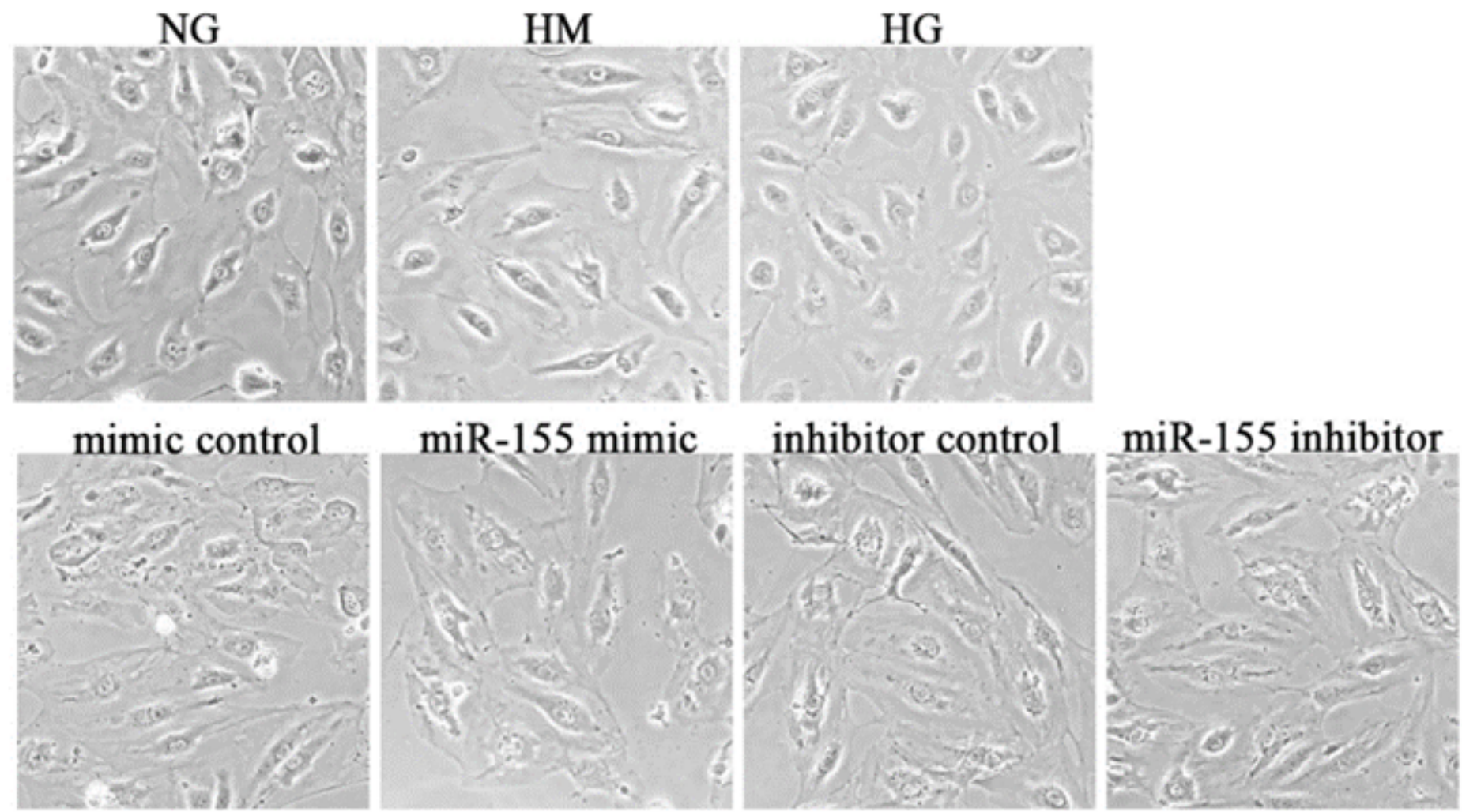

\section{Figure 1}

Light microscope results of HRGEC cell growth under different conditions. NG: normal glucose group; HM: hypertonic group; HG: high glucose group; mimic control: high glucose + mimic negative control; miR-155 mimic: high glucose +miR-155 mimic; Inhibitor control: high glucose + inhibitor negative control; miR-155 inhibitor: high glucose + miR-155 inhibitor $(\times 20)$. 

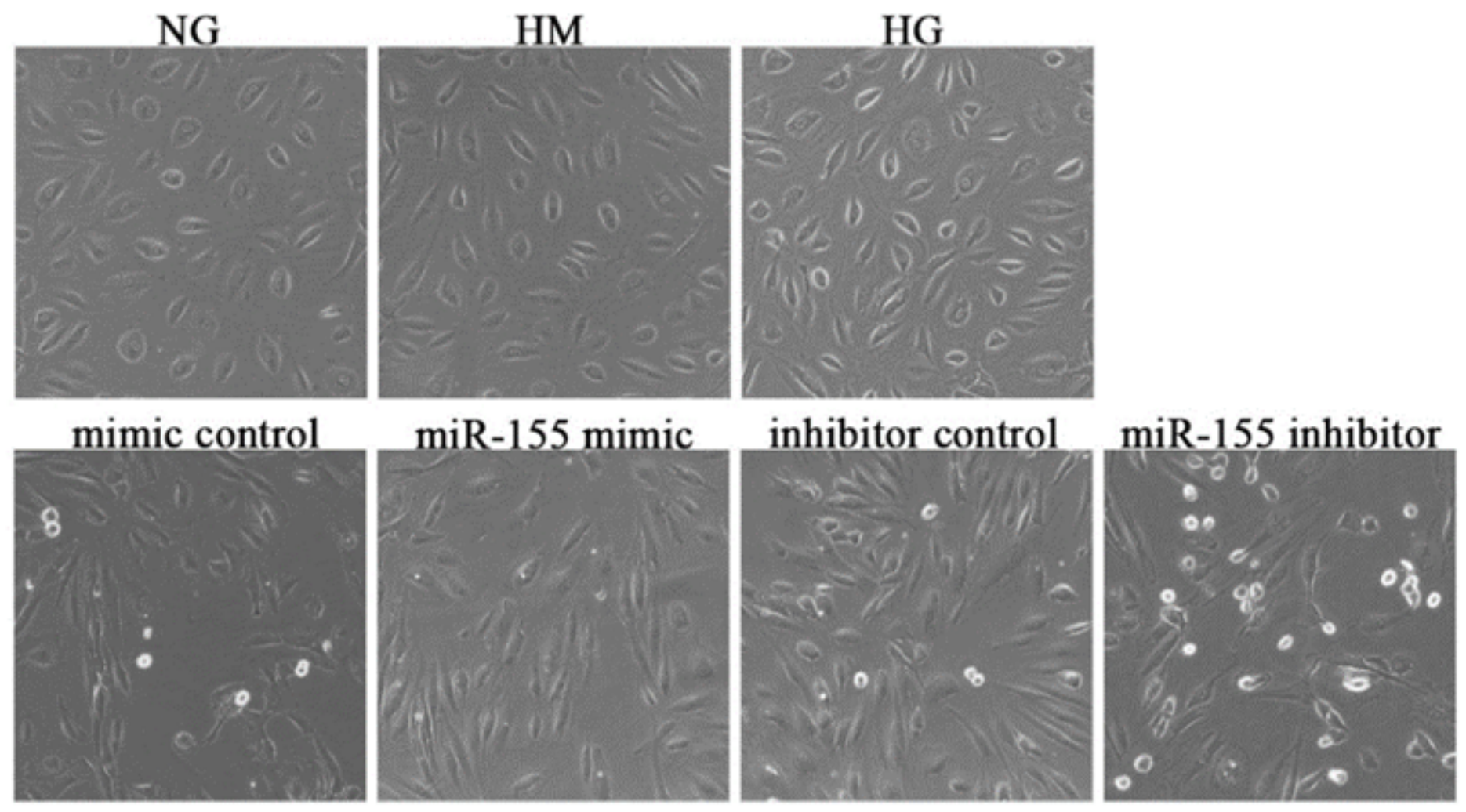

Figure 2

Light microscope results of apoptosis of HRGEC cells under different conditions. NG: normal glucose group; HM: hypertonic group; HG: high glucose group; Mimic control: high glucose + mimic negative control; miR-155 mimic: high glucose +miR-155 mimic; Inhibitor control: high glucose + inhibitor negative control; miR-155 inhibitor: high glucose + miR-155 inhibitor (×20).

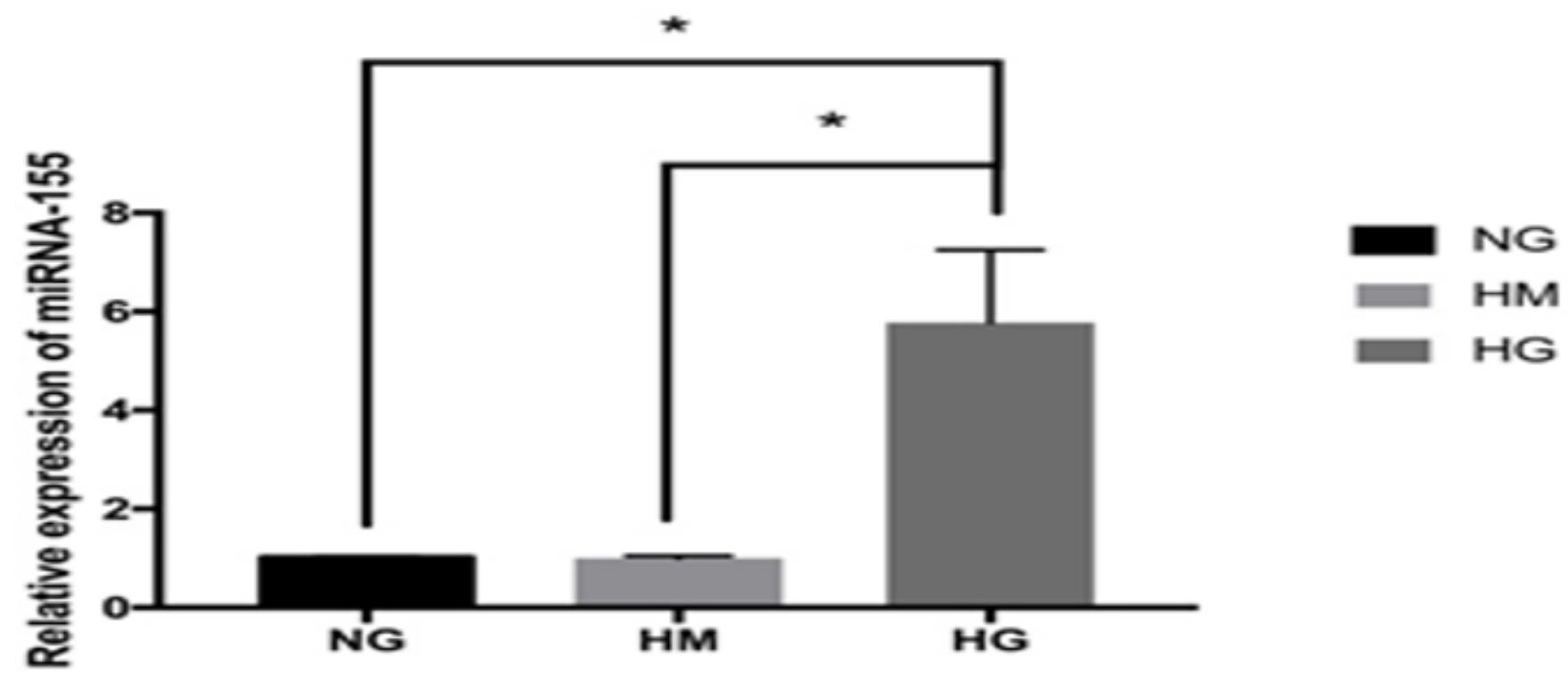

Figure 3 
The relative expression level of miRNA-155 in HRGEC cells after corresponding stimulation.NG: normal sugar group; HM: Hypertonic group; HG: high glucose group. ${ }^{*} \mathrm{P}<0.05$.

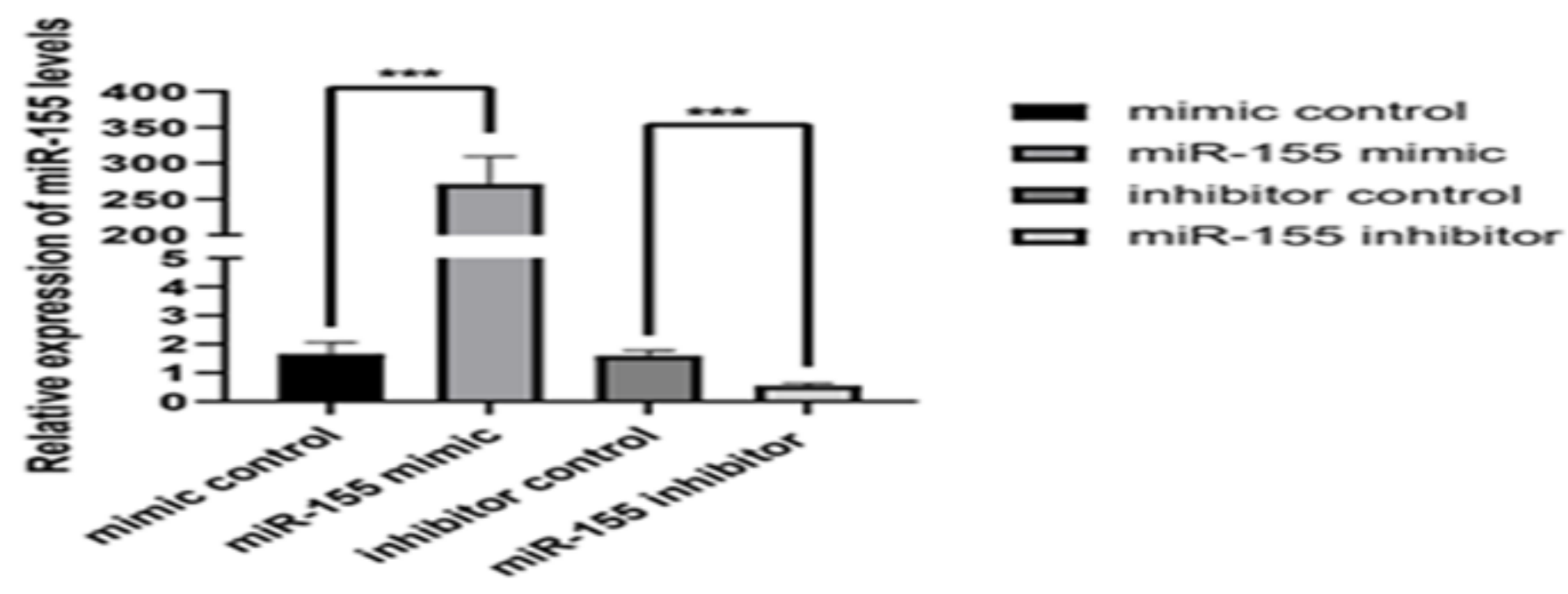

Figure 4

Expression levels of miR-155 after transfection with miR-155 mimic, mimic control, miR-155 inhibitor and inhibitor control. mimic control: mimic negative control; Inhibitor control: inhibitor negative control. $* * * \mathrm{P}<0.001$.

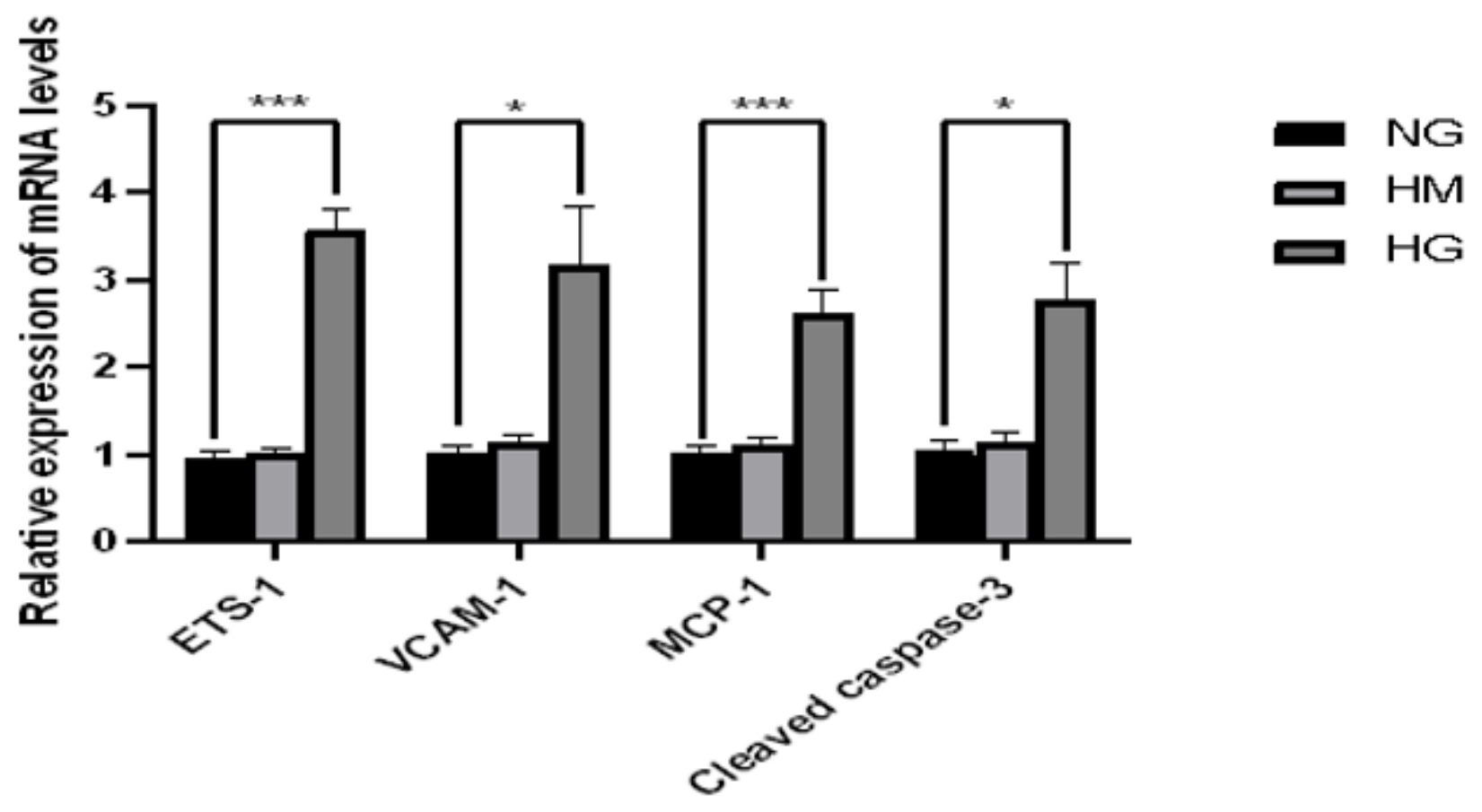

Figure 5

The mRNA expression levels of ETS-1 and its downstream factors in HRGEC after corresponding stimulation.NG: normal glucose group; HM: Hypertonic group; HG: high glucose group. ${ }^{\star} P<0.05$. $\star \star \star P<0.001$. 
A

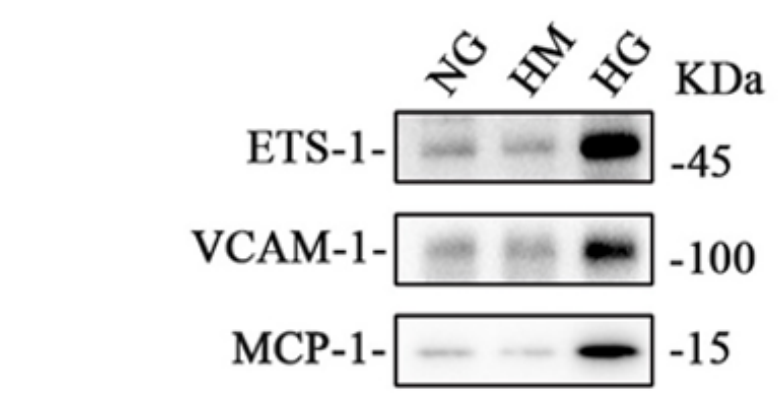

Cleaved caspase-3- $\longrightarrow \quad-15$

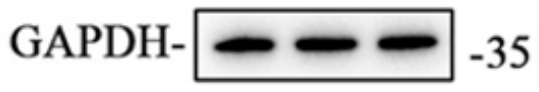

B
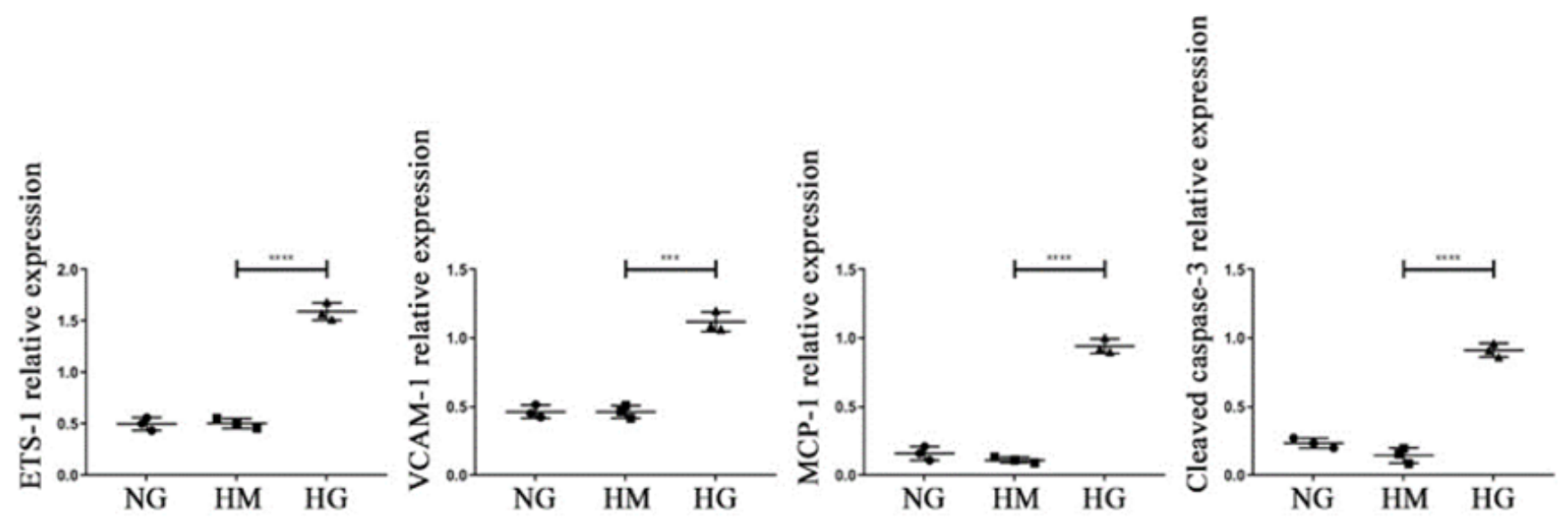

Figure 6

The protein expression levels (A) of and quantitative analysis (B) of the relative expression levels of ETS1 and its downstream factors in HRGEC stimulated by high glucose. NG: normal glucose group; HM: Hypertonic group; HG: high glucose group. ${ }^{*} * \mathrm{P}<0.001$. 
A
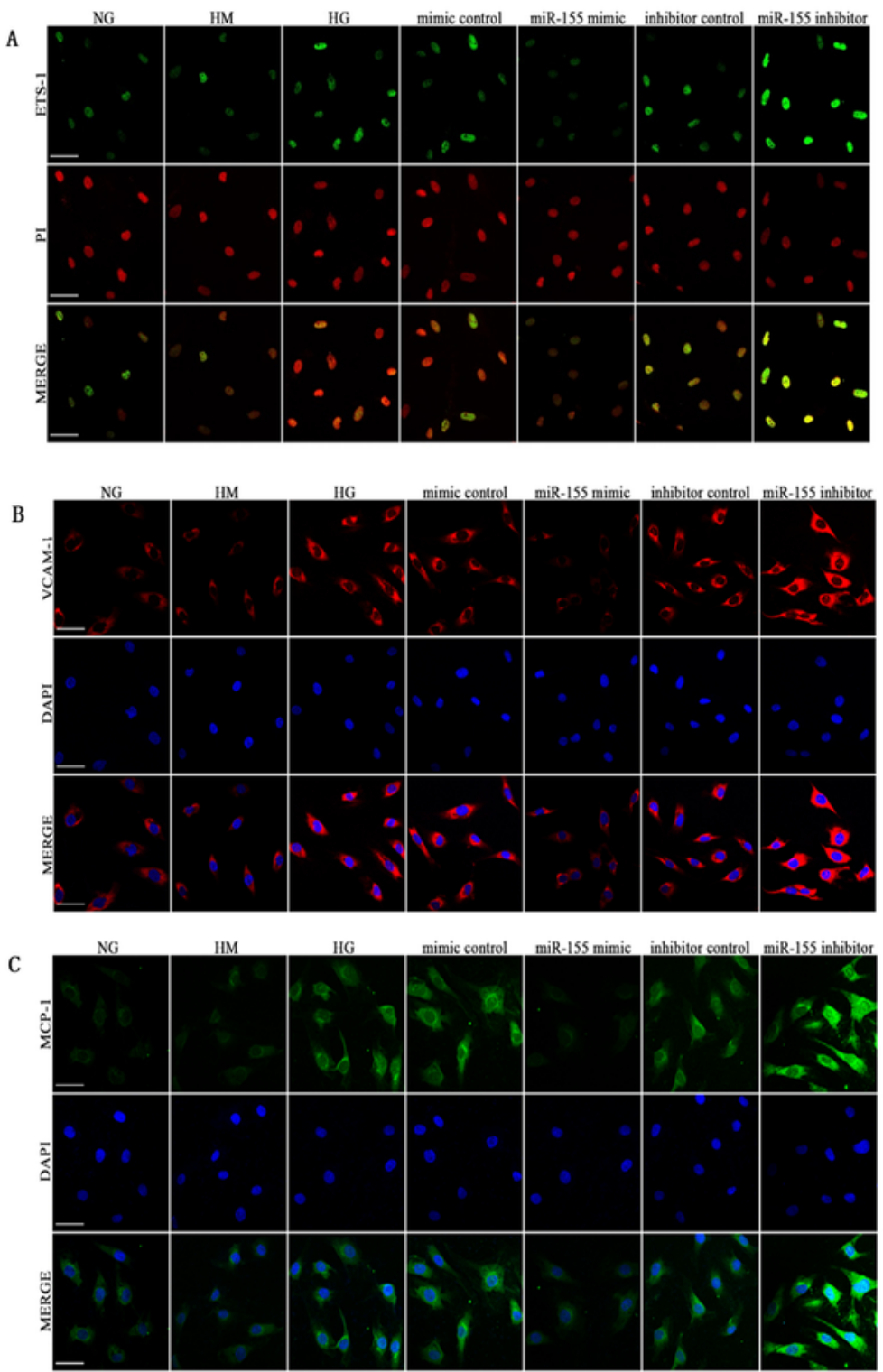

D

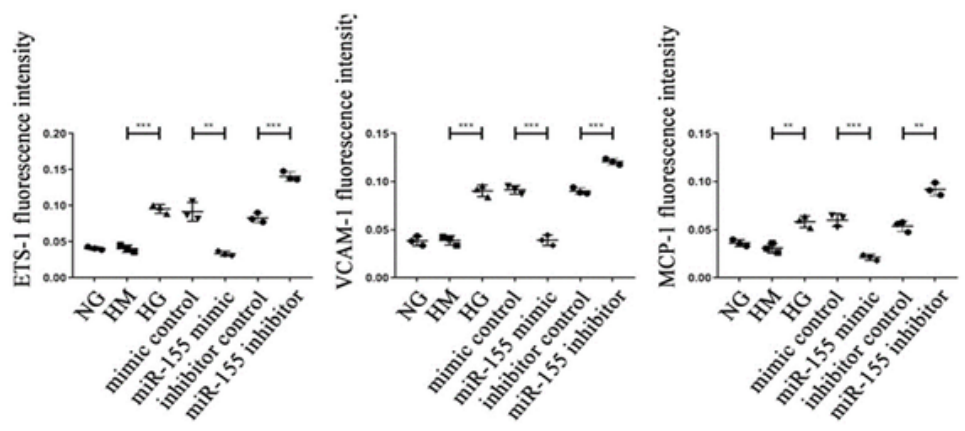

\section{Figure 7}

Immunofluorescence of ETS-1 (A) $\square \mathrm{VCAM}-1(\mathrm{~B}) \square \mathrm{MCP}-1$ (C) and quantitative immunofluorescence analysis (D) of ETS-1, VCAM-1 and MCP-1 in HRGEC with high glucose or high glucose +miR-155 transfection. NG: normal glucose group; HM: Hypertonic group; HG: high glucose group; mimic control: high glucose + mimic negative control; miR-155 mimic: high glucose +miR-155 mimic; Inhibitor control: high glucose + 
inhibitor negative control; miR-155 inhibitor: high glucose + miR-155 inhibitor. bar=50 $\mu \mathrm{m}$. $\star \star \mathrm{P}<0.01 .{ }^{\star *} \mathrm{P}<0.001$.

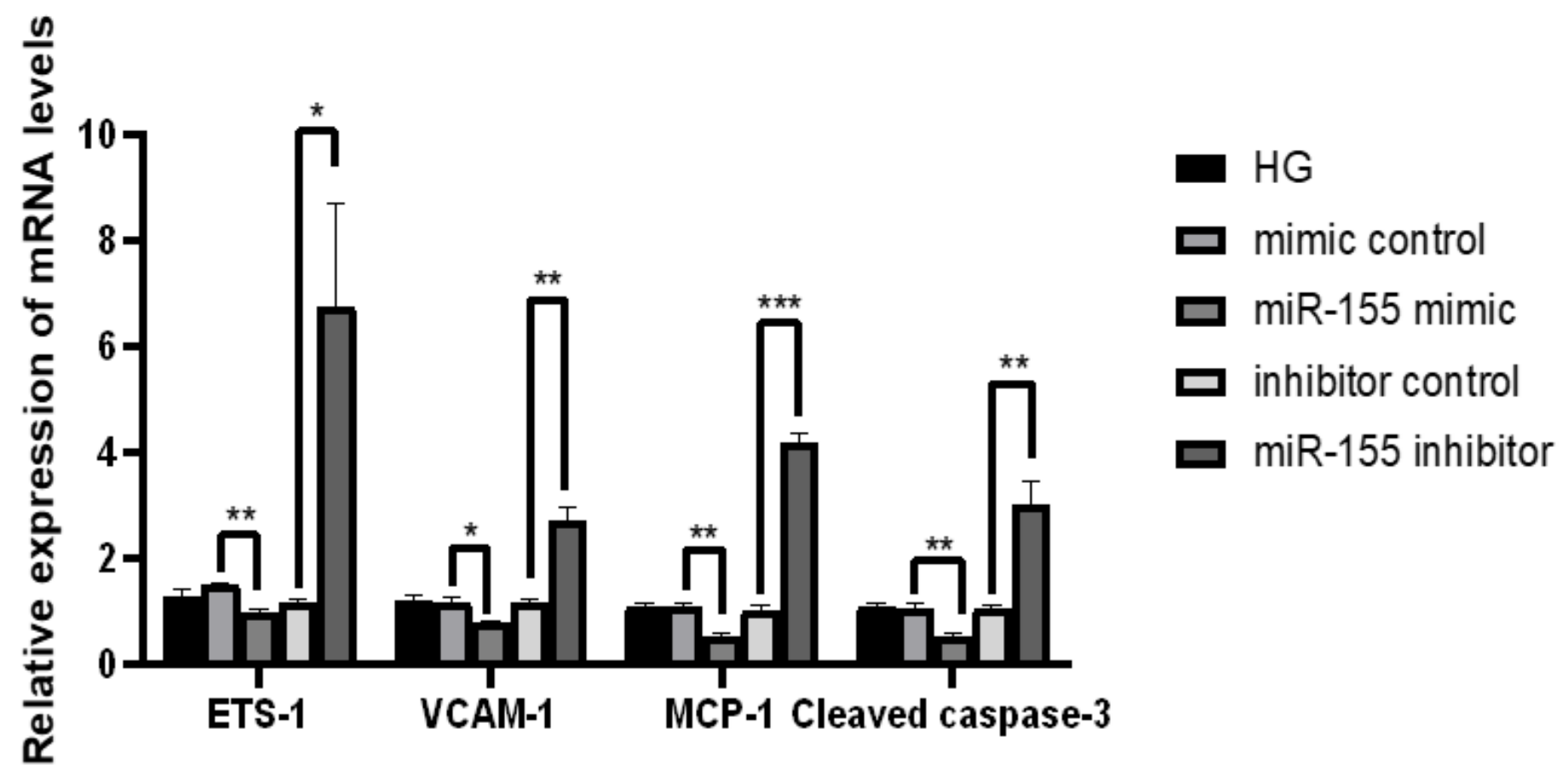

Figure 8

The mRNA expression levels of ETS-1 and its downstream factors in HRGEC with high glucose stimulation after miR-155 transfection. HG: high glucose control group; mimic control: high glucose + mimic negative control; miR-155 mimic: high glucose +miR-155 mimic; Inhibitor control: high glucose + inhibitor negative control; miR-155 inhibitor: high glucose + miR-155 inhibitor. ${ }^{*} P<0.05 .{ }^{* \star *} \mathrm{P}<0.001$. 
A

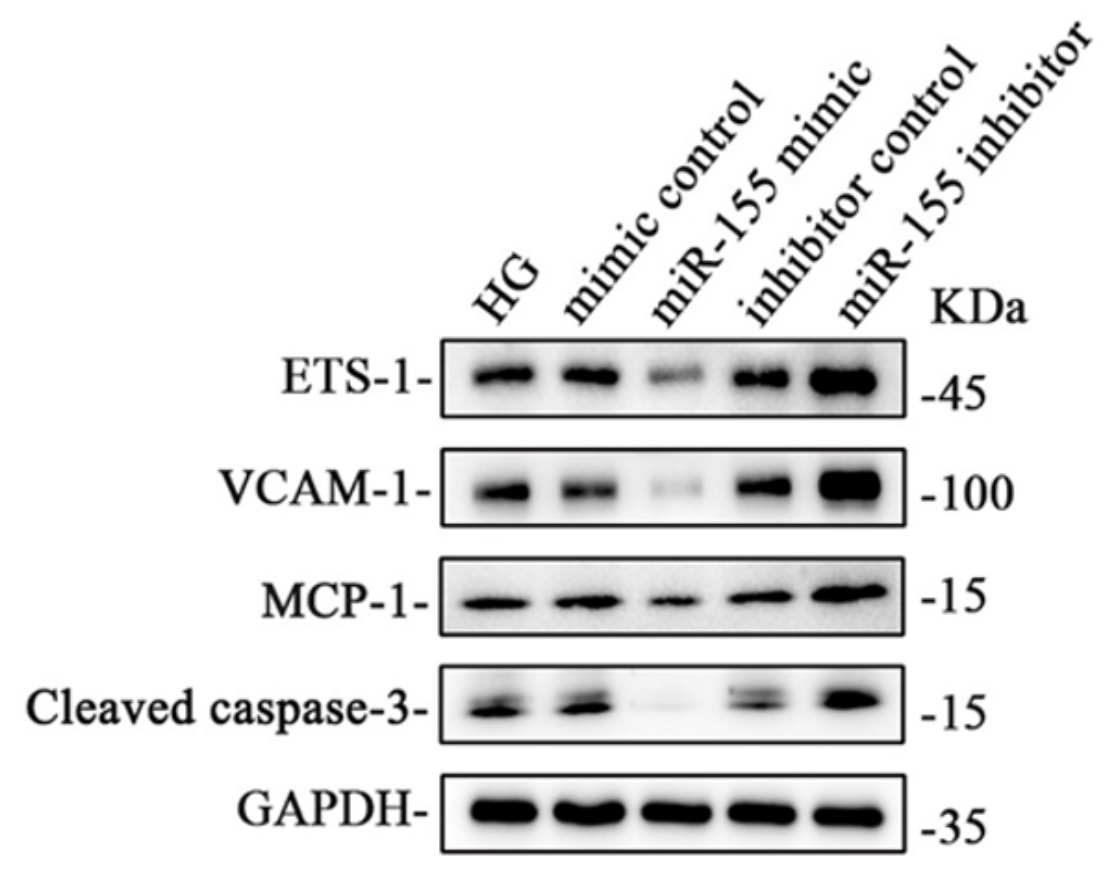

B
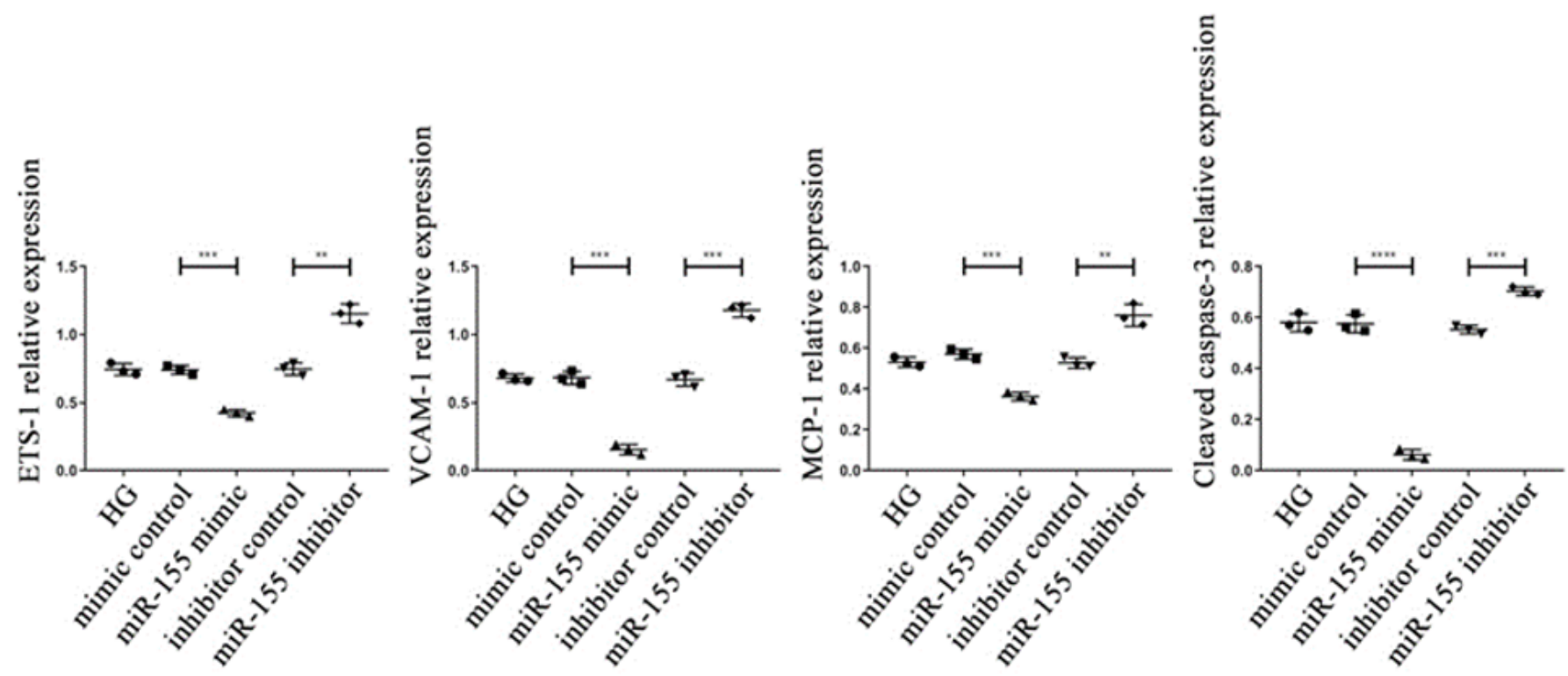

Figure 9

The protein expression level (A) and quantitative analysis (B) of ETS-1 and its downstream factors after transfection of miR-155 in HRGEC with high glucose stimulation. HG: high glucose control group; mimic control: high glucose + mimic negative control; miR-155 mimic: high glucose +miR-155 mimic; Inhibitor control: high glucose + inhibitor negative control; miR-155 inhibitor: high glucose + miR-155 inhibitor. ${ }^{\star} * \mathrm{P}<0.01 .{ }^{* \star *} \mathrm{P}<0.001$. 


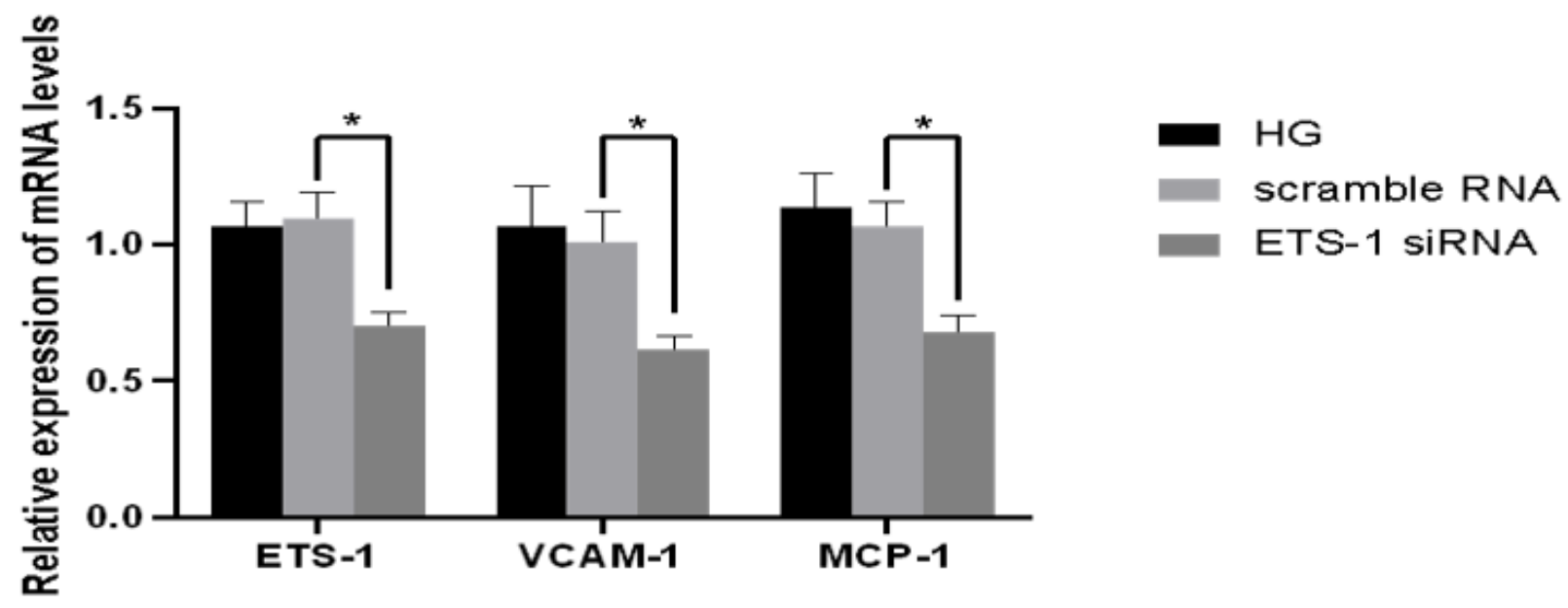

Figure 10

The mRNA levels of ETS-1 $\triangle$ VCAM-1 and MCP-1 in HRGEC with high glucose and high glucose +ETS-1 siRNA. HG: high glucose group; Scramble RNA: high glucose + scramble RNA; ETS-1 siRNA: high glucose +ETS-1 siRNA. *P<0.05. 
A

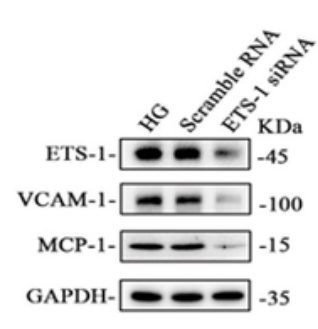

B
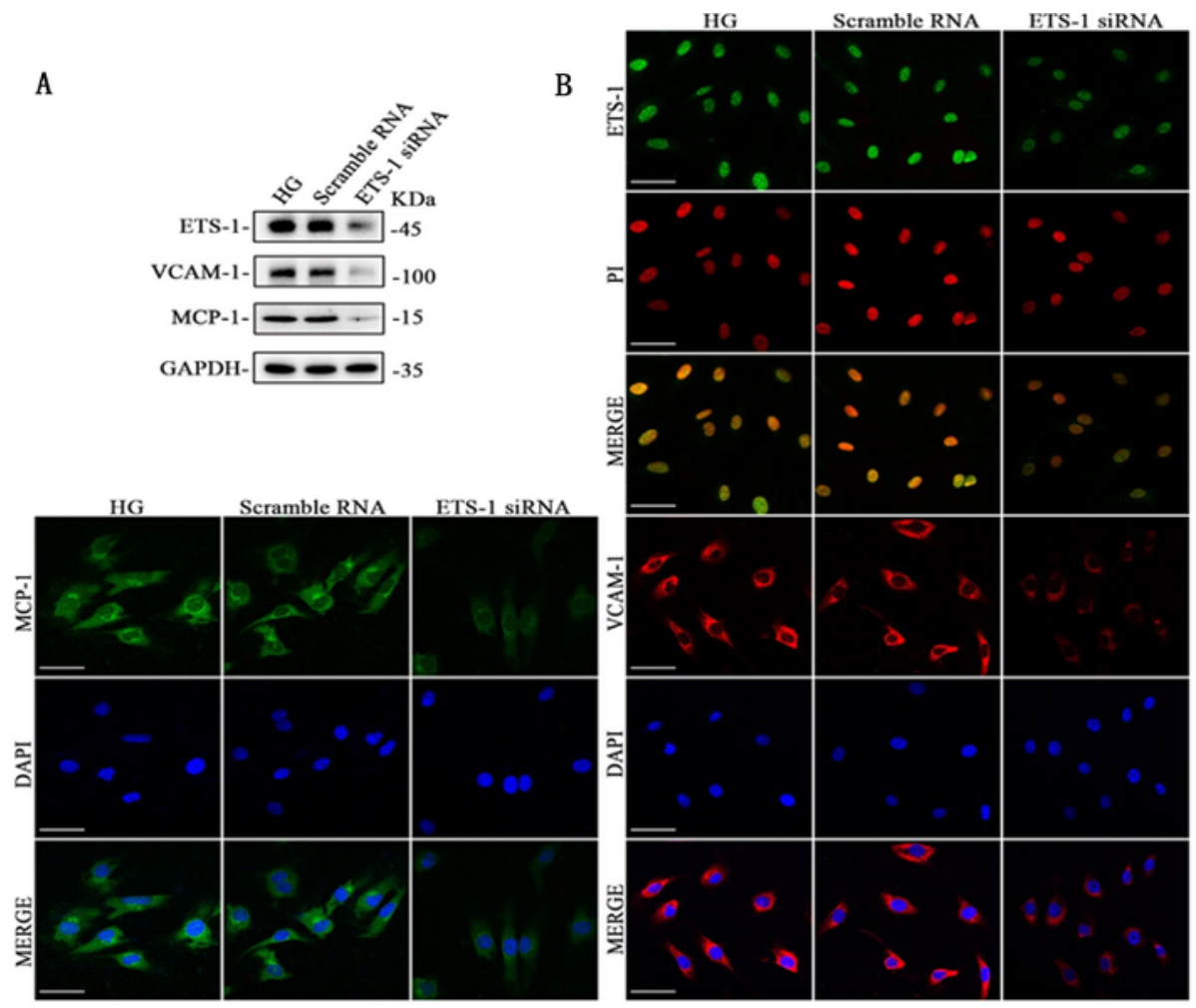

$\mathrm{C}$
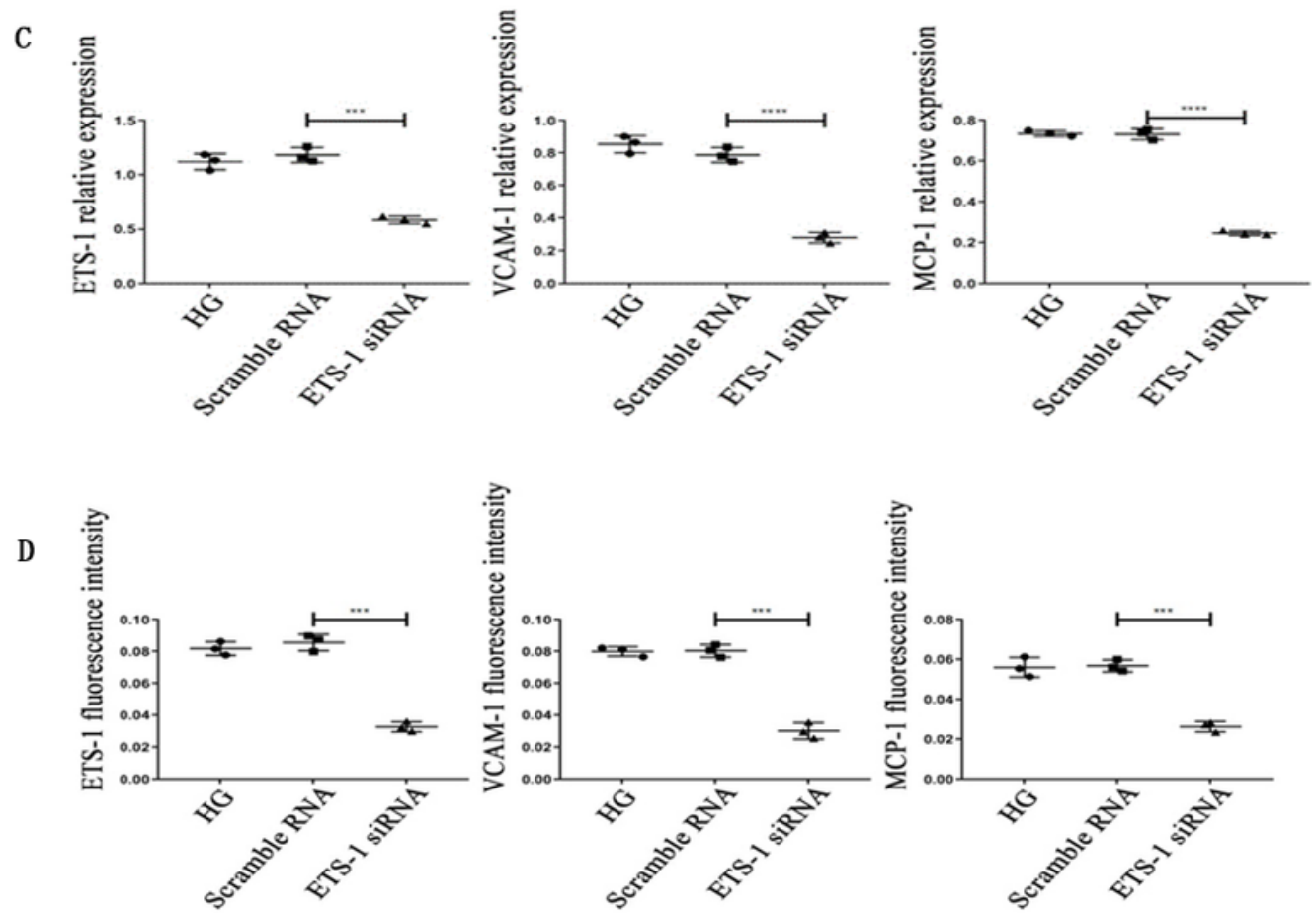

\section{Figure 11}

The protein levels (WB:A; IF:B)and quantitative analysis(WB:C; IF:D) of ETS-1区VCAM-1 and MCP-1 in HRGEC with high glucose and high glucose +ETS-1 siRNA. HG: high glucose group; Scramble RNA: high glucose + scramble RNA; ETS-1 siRNA: high glucose +ETS-1 siRNA. Bar $=50 \mu \mathrm{m} .{ }^{\star \star *} \mathrm{P}<0.001$ 